\title{
LAS INSCRIPCIONES REGISTRALES DE LAS ASOCIACIONES DE CANALISTAS UN CASO PARTICULAR: LA ASOCIACION DE CANALISTAS DEL EMBALSE COGOTI
}

\author{
Manuel Antonio Cortés Barrientos \\ Abogado \\ Profesor de La Escuela de Derecho \\ Universidad Católica del Norte \\ Sede Coquimbo
}

Las Asociaciones de Canalistas constituyen una de las formas que el legislador ha dado a las organizaciones de usuarios de derechos de aprovechamiento de aguas, para llevar a cabo sus fines propios.

En la especie, se refiere el presente análisis a la Asociación de Canalistas del Embalse Cogotí (ACEC), que ha producido en el devenir del tiempo, discordancias en cuanto al registro de los usuarios que la integran y de los derechos de aprovechamiento de aguas de los cuales son titulares de dominio, derivadas de duplicidades generadas en sus registros conservatorios.

El Embalse Cogotí que acumula la totalidad de las aguas de los Ríos Pama y Cogotí en la confluencia de éstos para formar el Río Huatulame, en la Provincia de Limarí, es en la actualidad la fuente que asegura el riego de la zona agrícola más rica y desarrollada de la Cuarta Región, entregando sus recursos hídricos a las plantaciones de viñedos de uvas de exportación más tempranas y de mayor calidad en el país.

\section{I.- CREACION DE LA ASOCIACION}

La ACEC, es una persona jurídica, cuyos estatutos fueron reducidos a escritura pública el 6 de junio de 1953 ante el Notario de Santiago don Herman Chadwick V.

Los referidos estatutos fueron aprobados con arreglo a lo prescrito en el artículo $7^{\circ}$ de la Ley 9.909 de 25 de agosto de 1950.

Según tal escritura, indica que le es aplicable también la normativa del Código de Aguas de 1951 y la Ley de riego.

En el mismo texto se agrega, conjuntamente con designarse Delegado por la $\mathrm{Di}$ rección General de Obras Públicas, que le son aplicables las normas de el artículo $7^{\circ}$ de 
la Ley № 4.445 del 10 de Octubre de 1928, modificada por el DFL № 340 desde 20 de mayo de 1931.

Este texto estatutario al ser aprobado por la Resolución № 1.239 de 4 de julio de 1953 del Ministerio de Obras Públicas y Vías de Comunicación, lo fue conforme lo establecido en el artículo $7^{\circ}$ de la Ley № 9.662 de 22 de diciembre de 1950.

\section{II .- SOMERO ANALISIS DE LAS NORMAS}

A) El artículo $7^{\circ}$ de la Ley 4.445 de 10 de octubre de 1928 , fue derogado por el DFL № 340 de 20 de mayo de 1931, que reemplazó su texto por el que dicha norma consigna.

Por consiguiente, en la especie lo referido a la Ley 4.445 deberá entenderse siempre con relación a lo prescrito en el DFL 340 que señala: "Artículo 7ㅇ․ El decreto que ordena la ejecución de la obra dispondrá que los propietarios beneficiados por ella, se constituyan en Asociación de Canalistas, que se regirán por las disposiciones de la Ley № 2139 de 9 de noviembre de 1908".

B) La Ley № 2139 sobre Asociaciones de Canalistas publicada en el Diario Oficial de 20 de noviembre de 1908, establece en su artículo primero que serán personas jurídicas, las asociaciones formadas por dueños de canales que se constituyan conforme el art. 20 de dicho cuerpo legal con el objeto de tomar el agua del caudal matriz y repartirla entre los accionistas, y conservar y mejorar los acueductos.

El art. 20 de la misma ley señala que las asociaciones de canalistas, deberán constituirse por escritura pública, estableciendo en ella un domicilio, y presentar sus estatutos a la aprobación del Presidente de la República .

El art. $5^{\circ}$ del mismo cuerpo legal señala que los actos y contratos traslaticios de dominio, respecto de los regadores de agua, se perfeccionarán por escritura pública y, la tradición de los mismos operará por la inscripción del respectivo acto o contrato en un registro especial, que se abrirá en cada oficina departamental del Conservador de Bienes Raíces y, que se llevará conforme el Reglamento que dicte el Presidente de la República.

Señala asimismo esta disposición que, sin perjuicio de las inscripciones prescritas en el art. 687 del Código Civil, los derechos de agua se inscribirán también, en todo caso, en el registro del Conservador del Departamento, en que se encuentre ubicada la bocatoma de su canal matriz.

El art. 687 del Código Civil indica que, "la inscripción del título de dominio y de cualquier otro de los derechos reales mencionados en el artículo precedente, se hará en el registro conservatorio del departamento en que esté situado el inmue- 
ble, y si éste por su situación pertenece a varios departamentos, deberá hacerse la inscripción en el registro de cada uno de ellos."

C) El Reglamento para la Inscripción de actos y contratos traslaticios de dominio de regadores de agua, se dictó el 9 de agosto de 1910.

El art. $5^{\circ}$ de dicho reglamento, señaló que las inscripciones en él consignadas, se harían en la oficina del Conservador del departamento en que se encuentra ubicada la bocatoma del canal matriz.

Pero además, el art $6^{\circ}$ agregó "sin perjuicio de las inscripciones de que trata este reglamento, siempre que se presente a un Conservador para su inscripción, un título de dominio de un fundo o un establecimiento industrial, en que aparezcan destinados regadores de agua de los señalados en la Ley 2139, el Conservador dejará constancia de la inscripción de los regadores de agua afectados por dicho acto y, transcribirá con cargo al interesado, la inscripción que haga al Conservador del departamento en que estuviere la bocatoma del canal matriz, a fin que este funcionario la anote al margen de la última inscripción de dominio de los mismos regadores, con la frase "vendidos como parte del inmueble "u otra semejante.

Agrega dicha norma que en lo que no estuviere previsto, regirán al respecto las prescripciones del Reglamento del Registro Conservatorio de Bienes Raíces de 24 de junio de 1857.

D) La Ley 9.909 publicada en el Diario Oficial de 28 de mayo de 1951, es la norma aprobatoria del texto definitivo del Código de Aguas, que además contiene un breve articulado.

En tal artículo $7^{0}$ se señala que al Departamento de Riego de la Dirección General de Obras Públicas, correspondería el cumplimiento de las funciones que el mismo Código encomendaba a la Dirección General de Aguas.

E) El Código de Aguas de 1951 en su Libro I, Título VI, arts. 81 a 145 regula las asociaciones de canalistas en cuanto a su formación y funcionamiento.

Les da el carácter de personas jurídicas, y señala en su art. 82 que se constituirán por escritura pública, con acuerdo de todos los dueños de derechos de aprovechamiento o a través del comparendo celebrado ante el Juez del departamento en que esté ubicada la bocatoma del canal principal.

El art. 87 señala los requisitos de la escritura constitutiva de una asociación de canalistas, y entre ellos se señala establecer un domicilio. 
El Código de Aguas, establece asimismo el Registro de Aguas en los Conservadores de Bienes Raíces, donde se deben inscribir los títulos que se indican en su articulado posterior.

Se indica, que la tradición de los derechos de aprovechamiento se efectuará por la inscripción del título en el Registro de Aguas del Conservador de Bienes Raíces.

El art. 239 señala en su número 1 que se deben inscribir en dicho registro de aguas, "los títulos constitutivos de una asociación de canalistas".

En el $\mathrm{N}^{2} 5$ de ese mismo artículo, se indica que se deben inscribir en este registro, los actos y contratos translaticios de dominio, de los derechos inscritos en conformidad al art. 240 del mismo Código y de los derechos inscritos en acuerdo a lo prescrito en la Ley 2319 sobre asociaciones de canalistas.

El art. 241 del Código, señala que las inscripciones deberán hacerse en el Registro de Aguas del departamento en que se encuentre ubicada la bocatoma del canal matriz en el cauce natural, pero que, sin perjuicio de ellas, los Conservadores deberán anotar al margen de las inscripciones relativas a las Asociaciones de Canalistas o Comunidades de Agua, las mutaciones de dominio que se efectúen y que se refieran a ellas.

El art. 244 del Código señala, que se aplicarán a los derechos de aprovechamiento referidos en los arts. 239 y 240 del Código, inscritos en los registros de aguas de los Conservadores de Bienes Raíces, con posterioridad a la fecha de vigencia del Código, todas las disposiciones que rigen la propiedad inscrita.

Se agrega además que, se continuarán aplicando también estas disposiciones a los derechos de agua inscritos en conformidad a lo señalado en la Ley 2139 , aun cuando no se hubiere cumplido con lo ordenado en el inc. $2^{\circ}$ del art. $5^{\circ}$ de dicha ley, que se refiere justamente a que tales derechos no se hubieren inscrito en el registro conservador del departamento, en que estuviere ubicada la bocatoma del canal matriz.

El art. 302 del Código de Aguas indica que el Registro Especial de Aguas llevado por los Conservadores de Bienes Raíces, de conformidad a la ley 2139 constituirá el Registro de Aguas creado por el Código y, que no será necesario reinscribir los derechos de agua, inscritos de acuerdo a la Ley 2139 y que estuvieren vigentes.

El Título Final del Código de Aguas señala que desde la vigencia del mismo $-1^{\circ}$ 잉 de abril de 1951- quedan derogadas las leyes, ordenanzas y reglamentos preexistentes sobre las materias que en él se tratan, aun en lo que no fueren contrarias a él. 
F) La Ley 9.662 de 25 de agosto de 1950 publicada en el Diario Oficial de 22 de diciembre de 1950 , señala en su art. $7^{\circ}$ que el decreto que ordene la ejecución de una obra de regadío por el Estado, dispondrá que los propietarios beneficiados por ella, se constituyan en asociaciones de canalistas de conformidad con lo dispuesto en la Ley 2139 de 9 de noviembre de 1908.

G) El DFL 162 publicado en el Diario Oficial de 12 de marzo de 1969, sistematizó el texto del Código de Aguas de 1951, coordinándolo con las disposiciones de la Ley 16.640 .

Consecuencia de ello, se producen modificaciones en el texto mismo, que además en otros casos fueron consecuencia de leyes expresas dictadas al respecto.

Es así, como el art. 238 del Código de Aguas consigna que la Dirección General de Aguas deberá llevar un Registro Público de Aguas, sin hacer mención en su texto a los Registros de los Conservadores, salvo como más adelante se señalará.

En las disposiciones transitorias del mismo cuerpo legal, el art. $9^{\circ}$ señala que mientras el Presidente de la República no determine por Decreto Supremo, la fecha en que entrará en vigencia el Registro Público de Aguas referido en el art. 238, el Registro de Aguas de los Conservadores de Bienes Raíces, deberá inscribir los documentos que enumera.

En primer lugar se encuentran los títulos constitutivos de una asociación de canalistas $y$, en el quinto lugar todo acto que genere un cambio de titular de derecho de aprovechamiento, en los casos expresamente autorizados por la ley.

La letra c) del art. $9^{\circ}$ transitorio señala que sin perjuicio de las inscripciones que procedan, los Conservadores deberán anotar al margen de las inscripciones relativas a las Asociaciones de Canalistas o Comunidades de Aguas, todo acto que genere un cambio de titular de derecho de aprovechamiento en los casos expresamente autorizados por la ley.

H) El DFL 1.122 de 13 de agosto de 1981 publicado en el Diario Oficial de 29 de octubre de 1981, dictó el Código de Aguas en actual vigencia.

El Título VIII del Libro I del Código de Aguas, reglamenta el Registro de Aguas, que deberá ser llevado por los Conservadores de Bienes Raíces, donde han de inscibirse los títulos que indica.

El art. 114 №1 consigna entre los títulos que deberán inscribirse en el registro indicado, los constitutivos de una organización de usuarios.

El art. 112 del mismo Código señala que las normas que indica son las que regirán la forma y solemnidad de las inscripciones y, que en lo no previsto regirán las 
normas del Código Orgánico de Tribunales y el Reglamento del Registro Conservatorio de Bienes Raíces.

El art. 118 señala las normas de competencia para las inscripciones pertinentes, consignando en primer término que ellas se efectuarán en la comuna en que se encuentre ubicada la bocatoma del canal matriz en el cauce natural.

Seguidamente, consigna una norma para las aguas embalsadas, las que deberán hacerse en el Conservador que tenga competencia en la comuna en que se encuentre ubicado el embalse.

Y agrega en su último inciso que, sin perjuicio de las inscripciones que procedan, los Conservadores deberán anotar, al margen de las inscripciones relativas a las organizaciones de usuarios o de las comunidades de aguas, las mutaciones de dominio que se efectúen y que se refieran a ellas.

El art. 13 transitorio del Código de Aguas de 1981 consigna a la vez, que el actual Registro de Aguas que llevan los Conservadores de Bienes Raíces, constituirá el Registro de Aguas, establecido en el art 12 del Código de Aguas. Agrega que no será necesario reinscribir los derechos de aguas que estuvieren vigentes.

Las anteriores serían enumeradas y reseñadas someramente en las normas específicas que sobre esta materia se consigan en las disposiciones legales y reglamentarias aludidas.

\section{LAS ASIGNACIONES DE DERECHOS DE AGUAS}

Para establecer el dominio de las acciones de agua en que se encuentran divididos los derechos de aprovechamiento de aguas del Embalse Cogotí, en su origen es menester establecer que son los Decretos del Ministerio de Obras Públicas, dictados desde Febrero de 1945 en adelante, los que establecen su distribución.

Es a través de estos Decretos, que el Estado fue distribuyendo por la vía de la asignación, los derechos de aguas a sus usuarios, y estableciendo a la vez, las obligaciones de éstos con el Fisco relativas al pago de los mismos y suscripciones de las correspondientes escrituras dentro de un plazo determinado.

El más importante de estos Decretos, lo constituye el № 301 de febrero de 1945, que aprueba la nómina de distribución y destinación de las acciones del Embalse Cogotí.

En los meses de mayo y noviembre del mismo año, se dictan dos nuevos Decretos que corrigen la denominación de acciones ya efectuadas. 
En el año 1947, un nuevo decreto regulariza la asignación de aguas a las Comunidades Agrícolas, que aún carecían de dominio respecto de los bienes raíces que ocupaban, y otro tanto ocurre en agosto de 1950 respecto de las Comunidades Agrícolas de Huana y Potrerillo Bajo.

Posteriormente en agosto de 1953 se dictó el Decreto № 1592 que dejó sin efecto la asignación y distribución de 763,9 y, redujo a su vez asignaciones anteriores en 101,80 , redistribuyéndolas.

Con posterioridad existen otros Decretos que modifican propietarios en particular, y algunas relativamente genéricas como ocurre en enero de 1955 y en 1963.

Lo interesante desde el punto de vista jurídico está, en que el Decreto originario de distribución y asignación de aguas, ha tenido mutaciones diversas derivadas del acto de autoridad administrativa, independientemente de la transferencia o trasmisión de estos mismos derechos, conforme las reglas del derecho común.

\section{LOS REGANTES DEL EMBALSE COGOTI}

La ACEC tuvo a su creación, la totalidad de sus regantes en tierras cuya ubicación geográfica, era el antiguo departamento de Ovalle.

A consecuencia de ello, todos estos inmuebles se encontraban inscritos en el Registro de Propiedad del Conservador de Bienes Raíces de Ovalle.

Hecho que cobra importancia en función de lo prescrito en el art. 687 del Código Civil, ya transcrito en forma precedente y, habida consideración también a las normas prohibitivas de enajenación de los derechos de aprovechamiento de aguas, en forma independiente de las tierras que regaban.

Esta norma que ha existido en diversos períodos de nuestra historia legislativa nacional, tuvo además especial relevancia en los decretos de asignación de aguas ya referidos.

Debe también tomarse en cuenta la situación del desaparecido Departamento de Combarbalá y sus variables en la división política administrativa del país, constituyendo en el presente sólo una comuna dentro de la Provincia del Limarí. 


\section{CONCLUSIONES}

1. La ACEC es una persona jurídica, constituida en conformidad a la ley y cuyos estatutos fueron aprobados por el Presidente de la República, conforme el Decreto Supremo que le da existencia.

En consecuencia, su calidad de persona jurídica regida por el Código de Aguas, no concluirá, sino en la forma y solemnidades que su propia normativa de constitución señale.

Se debe tener presente, que la calidad de persona jurídica, adquirida conforme la ley vigente a la fecha de su constitución subsiste aunque ésta pierda después su fuerza legal (art. $11^{\circ}$ relacionado con el art. $3^{\circ}$ de la Ley de Efecto Retroactivo de las Leyes).

2. La ACEC, tiene como su domicilio conforme sus estatutos y de acuerdo a la legalidad vigente, la ciudad de Ovalle.

Conforme ello y de conformidad con las disposiciones vigentes a la época, y aún en la actualidad, se deben inscribir los títulos correspondientes a la organización de usuarios en el Registro de Propiedad del Aguas del Conservador de Bienes Raíces de Ovalle.

3. La ACEC, como organización de usuarios, se encuentra correctamente inscrita en el lugar de su domicilio, la ciudad de Ovalle.

4. De conformidad a las normas existentes en el pasado $y$, a las actualmente vigentes, las mutaciones en el dominio que afecten a los derechos de aprovechamiento de aguas inscritos en las Asociaciones de Canalistas u organizaciones de usuarios, deben asimismo anotarse al margen de la misma inscripción, señalando su transferencia o trasmisión, y efectuarse la nueva inscripción en el mismo registro.

El art. 114 № 5 del actual Código de Aguas indica que en el Registro de Propiedad de Aguas del Conservador de Bienes Raíces, se deben inscribir los actos y contratos que constituyan traslaciones de dominio de los derechos de aprovechamiento de aguas, a que se refieren los números anteriores.

$Y$ en el $N^{2} 1$ se señala, que se inscriben en el Conservador los títulos constitutivos de una organización de usuarios.

De lo cual se colige, que igualmente en el Registro de Aguas en que se encuentre inscrita la Asociación de Canalistas, se deberá efectuar la inscripción de los derechos de aprovechamiento de aguas, a ellas adscritos.

5. En la especie, la ACEC tiene su domicilio legal en la ciudad de Ovalle y, en consecuencia, su inscripción en el Registro de Propiedad de Aguas del Conservador de Bienes Raíces de Ovalle, se ha efectuado en conformidad a la ley y, en conse- 
cuencia, en ella, se deben, asimismo practicar las inscripciones que se deriven, en la forma ya indicada.

6. Lo anterior, sin perjuicio de reconocer la vigencia de la norma del art. 118 del Código de Aguas, que establece que las inscripciones se practicarán, tratándose de aguas embalsadas, en el Conservador de Bienes Raíces que tenga competencia en la comuna donde se encuentre ubicado el mismo Embalse.

Respecto de esta situación, atendido el hecho que el Embalse Cogotí se encuentra ubicado en la comuna de Combarbalá, procederá también la inscripción de los derechos de aprovechamiento de aguas en dicho Conservador.

En consecuencia, procederá que tales derechos de aprovechamiento mantengan una doble inscripción, tanto respecto de la organización de usuarios en Ovalle, como de sus propietarios individuales en Combarbalá.

Existiendo desde su origen, la inscripción primaria en el Conservador de Ovalle, habrá de procederse con la copia de la correspondiente inscripción de dominio, su certificación de vigencia, sus certificados de hipotecas y gravámenes y de juicio y litigio otorgada en fecha reciente por este Conservador, a su nueva inscripción en el Conservador de Combarbalá.

Sólo de esta manera se salvaguardará la seguridad registral y, se dará cabal cumplimiento a las normas analizadas sobre la materia. 